\title{
Role of Exosomal Intercellular Communications in Diabetic Vascular Complications in Experimental Animals
}

\author{
Noura N. Ballasy ${ }^{\mathrm{a}}$, Vaibhav Patel ${ }^{\mathrm{b}}$, Noha I. Hussien ${ }^{\mathrm{a}}$, Ola A. El-Gohary ${ }^{\mathrm{a}}$, Alaa El Deen El- \\ Talees ${ }^{\mathrm{a}}$.
}

a Department of physiology, Benha faculty of medicine, Banha University, Egypt.

${ }^{\mathrm{b}}$ Department of physiology and pharmacology, Cumming school of medicine, University of Calgary, Calgary, Canada.

Correspondence to: Noura N. Ballasy, Department of physiology, Benha faculty of medicine, Banha University, Egypt.

Email:

nora.arafat@fmed.bu.edu.eg

Received: 14 March 2020

Accepted: 22 June 2020

\begin{abstract}
:
Background: Cardiovascular complications are the main cause of death in diabetic patients. Intercellular communications may link diabetes to the cardiovascular complications. Exosomes are now emerging as a key mediator of intercellular communications. Aim: This study aimed to study the possible role of intercellular communications between adipose derived stem cells (ASCs) and vascular smooth muscle cells (VSMCs) in the development of diabetic vascular complications. Methods: To create an in vitro model which can mimic diabetic conditions, primary mouse ASCs from mouse aortic perivascular adipose tissue (PVAT) were treated with a cocktail of LPS, high glucose and Palmitate. ASCs conditioned medium were collected, and exosomes were isolated. Migratory capacity of vascular smooth muscle cells (VSMCs) incubated with ASCs derived exosomes were assessed via scratch assay. Results: Exosomes derived from our in vitro model of ASCs promoted migration of VSMCs. Conclusion: These data
\end{abstract} suggest an association between diabetes and progression of vascular dysfunction via intercellular communications mediated by exosomes derived from perivascular adipose tissue.

Key words: Diabetes, Exosomes, ASCs, VSMCs.

Abbreviations: ASCs; adipose derived stem cells, VSMCs; Vascular smooth muscle cells, PVAT; perivascular adipose tissue. 



\section{Introduction}

According to the international diabetes federation estimation, out of 415 million people with diabetes, $91 \%$ have been diagnosed with type 2 diabetes mellitus (T2DM). Moreover, the number of cases is expected to reach 642 million by 2040 (1). Cardiovascular diseases are the main cause of morbidity and mortality in type 2 diabetes(2). While perivascular adipose tissue (PVAT) was initially considered as an inert tissue which provides mechanical support for vasculature, and acts as a passive reservoir for fat storage, recently it becomes clear that this fat depot is an active dynamic endocrine organ whose phenotype and secretory behavior contribute to the pathogenesis of cardiovascular diseases(3). Adipose tissue dysfunction in type 2 diabetes is one of the main contributing factors to type 2 diabetes related complications(4).

In contrast to white adipose tissue (WAT), brown adipose tissue (BAT) can protect against metabolic dysfunction through regulation of metabolic fuel and energy expenditure(5). However, sustained low grade inflammation can alter the PVAT phenotype, thus impairing its thermogenic and metabolic functions $(6,7)$. Beside its endocrine function, adipose tissue is now considered as the preferred source of stem cells, because of its abundance and the ease of harvesting. Adipose derived stem cells (ASCs) possess high pluripotency and proliferative capacity (8-10), and secret a wide variety of cytokines and growth factors. Moreover, its conditioned media have been shown to provide functional improvement similar to that provided by the ASCs, which raises concerns about the possible paracrine effects of ASCs both during health and diseases(11-13).

All these characteristics make it an ideal model for in vitro studies, clinical translation and regenerative medicine. However, metabolic diseases driven inflammatory changes may impair ASCs abilities $(8,14)$. One of the main properties of ASCs is its capability to promote angiogenesis(15), ennert et al.,2014 have showed that ASCs, from diabetic mice have diminished angiogenic capacities which failed to promote wound healing(16). 
Exosomes are a subtype of extracellular vesicles with a diameter typically below 100 $\mathrm{nm}$; they are secreted from various types of cells. Exosomes emerge as an intercellular communicator via transferring its cargo (mRNAs, microRNAs (miRNA), and proteins) to target cells thus inducing genetic and epigenetic regulations in recipient cells(17).

Multidirectional cross talk between cells plays a pivotal role in metabolic disorders(18). Eljaafari et al., group have used ASC- mononuclear cell (MNC) coculture model to show that, ASCs obtained from obese subjects contribute to adipose tissue inflammation via deviation of the immune response from type 1 helper $\mathrm{T}$ cells towards the inflammatory type 17 helper $\mathrm{T}$ cells .This phenotype switching was associated with enhancement of inflammatory cytokines secretion by MNCs (19).

Thus, the presence of an in vitro model of ASCs which could mimic the metabolic dysfunction and the inflammatory status in obesity and type 2 diabetes, can help us to gain better insight into the molecular mechanisms of metabolic disorders.

Additionally, it can help us to study the precise role of these phenotypically altered
ASCs in the pathophysiology of vascular complications in diabetes, paving the way to the development of novel therapeutic strategies.

\section{Material and methods}

This is an in vitro prospective study to figure out the role of ASCs derived exosomes on VSMCs phenotype switching.

These experiments were carried out in Dr. Patel's lab in Libin Cardiovascular institute of Alberta at the University of Calgary between December 2018 and June 2019.

6 samples were used for each group.

Animals

C57Bl/6J (wild type [wt]) mice were purchased from the Jackson Laboratory (Bar Harbor, Me) to be included in the study.

All experiments were conducted in accordance with the guidelines of the University of Calgary Animal Care and Use Committee and the Canadian Council of Animal Care, protocol number: AC17-0098.

\section{Cell Culture}

Isolation and culture of Vascular Smooth Muscle Cells (VSMCs) 
Vascular smooth muscle cells (VSMCs) were isolated from 8- to 10 -weeks old (2022) wild type mice aortas and cultured as following, the aortas were incubated with enzyme solution containing $1 \mathrm{mg} / \mathrm{ml}$ collagenase II (Worthington Biochemical, NC9870009) and $1 \mathrm{mg} / \mathrm{ml}$ elastase (Worthington Biochemical, NC9030467) at $37^{\circ} \mathrm{C}$ in $5 \% \mathrm{CO} 2$ incubator for 10 mins. The adventitial and inner layers of aorta were dissected off. The aortic media were cut into small pieces and incubated with enzyme solution for 90 mins at $37^{\circ} \mathrm{C}$ in $5 \% \mathrm{CO} 2$ incubator. After digestion, cells were washed and cultured with Gibco DMEM/F12 media (Thermo Fisher Scientific, 11330057) containing 20\% fetal bovine serum (Thermo fisher scientific, 26140079) supplemented with $1 \%$ penicillin/streptomycin (VWR, CA12001712). Cells were passaged when reached $100 \%$ confluency and cells from Passage (410) were used for the experiments (23).

Isolation and culture of adipose tissue derived stem cells (ASCs)

Primary ASCs from mouse aortic perivascular adipose tissue were isolated and cultured. The PVAT around the Aorta of male C57/BL6 mice, 14-20 weeks old (2426), was dissected. The tissue was transferred in the growth medium to the culture hood in a pre-weighted petri dish. the tissue was finely minced with scissors and digested with collagenase dispase (SigmaAldrich, 11097113001) for $60 \mathrm{~min}$ at $37^{\circ} \mathrm{C}$ with gentle shaking. After collagenase neutralization, the floating adipocytes were separated by centrifugation at $1700 \mathrm{rpm}$ for 10 mints at room temperature. The resulting pellet was resuspended in RBCs lysis buffer and left on ice for 5 minutes, the stromal vascular fraction (which contains the stem cells) was separated by centrifugation at $1700 \mathrm{rpm}$ for $10 \mathrm{mins}$ at room temperature, then the pellet was resuspend in Gibco DMEM/F12 media (Thermo Fisher Scientific, 11330057) containing 20\% fetal bovine serum (Thermo fisher scientific, 26140079) supplemented with $1 \%$ penicillin/streptomycin (VWR, CA12001712), and were plated in tissue culture flasks at $37^{\circ} \mathrm{C}$ in a $5 \% \quad \mathrm{CO}_{2}$ humidified atmosphere (27).

Construction of adipocyte stem cell model which can mimic obesity and diabetic conditions

Cells at passage 2-5 were used for all experiments. After reaching confluence, cells were cultured in exosomes depleted medium supplemented with $0.5 \%$ fetal 
bovine serum (Thermo fisher scientific, 26140079) and 1\% penicillin-streptomycin (VWR, CA12001-712) for 24 hours. To mimic diabetic conditions, exosomes depleted Growth medium was supplemented with palmitate 200 um (28), glucose $25 \mathrm{Mm}$ (in addition to glucose present in medium)(29) and lipopolysaccharides (LPS) $1 \mathrm{ug} / \mathrm{ml}$ (30) was used to prime ASCs for 24 more hours. Culture medium from primed ASCs (P-ASCs) was collected for exosomes isolation.

Cellular metabolic rate

Cellular oxygen consumption rate (OCR) and extracellular acidification rate (ECAR) were measured (model XFe, Seahorse Bioscience) according to the kit instruction. Briefly, cells were seeded in the Seahorse XF Cell Culture Microplate in the ASCs growth medium divided into two groups; control group and a group primed with the cocktail for 24 hours. In the next day the assay medium was prepared by supplementing Seahorse XF Base Medium (Agilent Technologies ,103575-100) with 1 $\mathrm{mM}$ pyruvate, $2 \mathrm{mM}$ glutamine, and $10 \mathrm{mM}$ glucose. Cells were then washed with assay medium once. After washing, assay medium was added to increase the volume to $180 \mu \mathrm{L}$. The plate was incubated at $37^{\circ} \mathrm{C}$ for 1 hour prior to the assay. A stressor mixer was prepared by combining oligomycin with FCCP in a single tube in the previously prepared assay medium. The indicated volume of stressor mix was added into every port A of hydrated sensor cartridge. The loaded sensor cartridge with the calibrant was plated into the Seahorse XFe Analyzer for calibration, then the cell culture microplate was loaded to begin the assay.

Exosomes isolation

Isolation and purification of adipocyte stem cells derived exosomes (ASCDEs)

ASCDEs were isolated and purified using a multistep centrifugation protocol. All centrifugation steps were carried out at $4^{\circ} \mathrm{C}$. The culture media were collected and precleared by sequential centrifugations at $2000 \times \mathrm{g}(20$ minutes $)$ and $10000 \times \mathrm{g}(30$ minutes) to eliminate dead cells, debris and microvesicles. The supernatant was centrifuged at $100,000 \times \mathrm{g}$ for 70 minutes with an ultracentrifuge (Beckman Coulter, XL-70, USA). The exosome pellet was diluted with phosphate buffered saline (PBS) and ultra-centrifuged again at 100,000 $\times \mathrm{g}$ for 70 minutes. The final pellet was resuspended in a small volume $(\sim 100 \mu \mathrm{l})$ of an appropriate buffer (31). 
Transmission electron microscopy analysis of the ultra-structures of the ASCDEs was performed (32). Protein-markers, namely, Tumor susceptibility gene 101 (TSG101) and CD81 were examined by western blot.

ASCDEs protein extraction and quantification

For protein extraction the exosomes resuspended in Ripa buffer with Complete protease inhibitor cocktail tablets, EDTAfree (Sigma-Aldrich, S8830-2TAB) and PhosSTOP phosphatase inhibitor cocktail tablets (Millipore Sigma, 4906837001) were diluted at 1:1 ratio in 2x STS sample buffer and left on ice for 30 minutes.

After 30 minutes the proteins were quantified using the he $D C$ (detergent compatible) protein assay (Bio Rad, 5000116) according to the kit instructions. Briefly, serial dilutions of the standards in PBS were generated according to the suggested dilutions to construct a standard curve.

Both the sample and standards were mixed with reagent $A^{\prime}$ and reagent $B$. The plate was incubated at room temperature for 20 minutes and analyzed using a spectrophotometer at $700 \mathrm{~nm}$.

Wound healing assay

VSMCs at passage 5 with density adjusted to $\left(1 \times 10^{5}\right)$ were grown in 24 well plates in Gibco DMEM/F12 media (Thermo Fisher Scientific, 11330057)containing 20\% fetal bovine serum (Thermo fisher scientific, 26140079) supplemented with $1 \%$ penicillin/streptomycin (VWR, CA12001712). At $80 \%$ confluence, cells were starved for 24 hours, then media was removed, and a straight-line scratch was made on the monolayer of VSMCs using $10 \mathrm{ul}$ plastic pipette tip. $25 \mathrm{ug} / \mathrm{ml}$ of exosomes in serum depleted medium were used for cell treatment.

Cells were then divided in to 3 groups, first group was supplemented with serum free medium for 24 hours, second group was treated with control ASCDEs and third group treated with primed ASCs derived exosomes (P-ASCDEs). For each well images were taken at 0 and 24 hours after scratch. Images were taken using camera system coupled to a microscope. Image $\mathrm{j}$ software was used to determine the wound 
healing percentage as following (Scratch wound area at $0 \mathrm{hr})-($ scratch wound area at $24 \mathrm{hrs}$ )/ Scratch wound area at $0 \mathrm{hr}$ (33).

Molecular biology

RT-PCR was used to detect gene expression of: Inflammatory markers (TNF-alpha, MCP-1, IL-6 and IL-10).

Quantitative real time PCR

For various genes, RNA expression levels were determined by TaqMan Real-time PCR (34). Total RNA was extracted from flashfrozen aorta tissue using TRIzol reagent, and cDNA was synthesized from $1 \mu \mathrm{g}$ RNA by using random hexamers.

For each gene, a standard curve was generated using known concentrations of cDNA $(0.01,0.1,1,10$ and $100 \mu \mathrm{g})$ as a function of cycle threshold (CT). Expression analysis of the reported genes was performed by TaqMan Real-time PCR using QuantStudio $^{\text {TM }} 3$ system (ThermoFisher Scientific, MA, USA). Data was analysed using QuantStudio ${ }^{\text {TM }}$ design and analysis software version 1.4.3. All samples were run in triplicates in 384 well plates. 18S rRNA was used as an endogenous control.
Table 1: Primers used for real time PCR

\begin{tabular}{lll}
\hline Mouse gene & Assay ID & Supplier \\
\hline MCP-1 & Mm.PT.58.42151692 & IDT \\
TNF-alpha & Mm.PT.58.12575861 & IDT \\
IL-6 & Mm.PT.58.10005566 & IDT \\
IL-10 & Mm.PT.58.13531087 & IDT \\
\hline Wester blotting &
\end{tabular}

Western blotting was used to detect protein expression of exosomes' specific markers (CD 81 and TSG-101). After protein extraction and quantification, proteins were separated in SDS-PAGE gels and transferred to Polyvinylidene fluoride (PVDF) membranes (Bio-Rad, 1620177, Canada). The membranes were soaked in blocking buffer (5\% nonfat dry milk in PBS with $0.05 \%$ Tween-20 (PBST) for $1 \mathrm{~h}$ at room temperature, and then incubated overnight at $4^{\circ} \mathrm{C}$ with the appropriate primary antibodies CD81 (Santa Cruz, ,SC-23962,1:500) and TSG-101 (Abcam, ab83,1:1000) diluted in the same blocking buffer. Next day the membranes were washed in TBST $0.1 \%$ (3X, 10 minutes each) and then incubated for $1 \mathrm{~h}$ at room temperature with the secondary antibodies diluted in the same blocking buffer. Immunoreactivity was detected by using Amersham ECL Prime (Thermo Scientific, 45-002-401). 
Statistical analysis

Quantitative data were given as mean \pm SD.

Statistical significance was tested using twotailed Student's $t$ test and one-way ANOVA test by the computer program Prism (GraphPad 8 Software). A value of $P<0.05$ was considered statistically significant.

\section{Results}

Upon exposure to stress, control ASCs (group I) were able to increase its basal OCR significantly $(\mathrm{p}<0.05)$ when compared to primed ASCs (group II). On the other hand, there was nonsignificant $(\mathrm{P}<0.05)$ difference between the ability of ASCs in both groups to increase their ECAR upon exposure to stress. (Chart 1\&2).

\section{Chart 1}

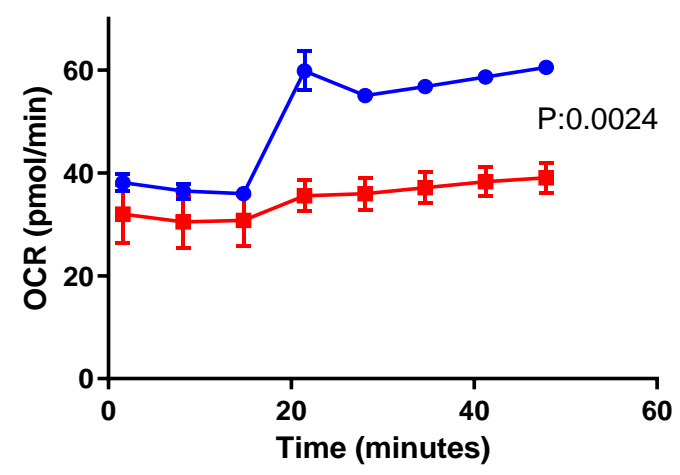

The mean and the standard error of the mean of OCR in control ASCs (group I) versus primed ASCs (group II) both at basal and stress conditions.

\section{Chart 2}

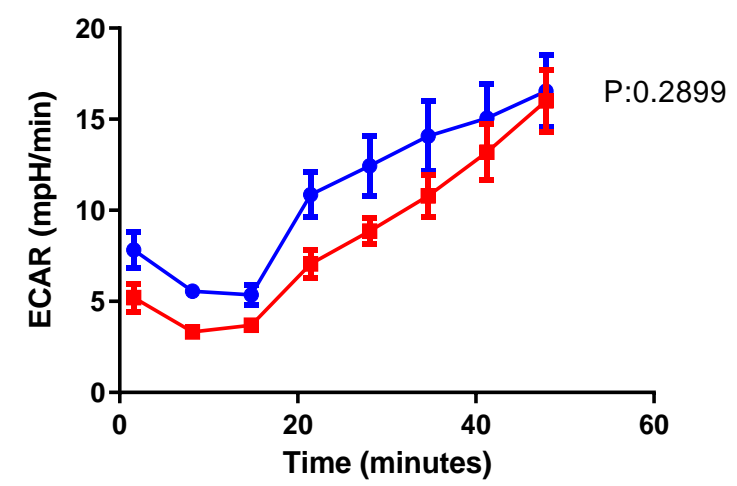

The mean and the standard error of the mean of ECAR in control ASCs (group I) versus primed ASCs (group II) both at basal and stress conditions.

There was a significant increase $(\mathrm{P}<0.05)$ in the inflammatory markers; MCP-1/18S expression in group II $(288.3 \pm 25.75)$ when compared with that of group I $(56.45 \pm 1.511)$ and significant increase in IL-6/18S expression in group II $(74.71 \pm 4.892)$ when compared with that of group I (16.86 \pm 1.959$)$. On the other hand, there was no statistically significant difference in the expression level of neither TNF-alpha/18S in group II $(0.001733 \pm 0.0002753)$ when compared with 
that of group I $(0.001333 \pm 0.0002275)$, or in IL-10 expression in group II $(0.001828 \pm 6.270 \mathrm{e}-005) \quad$ when compared with that of group I $(0.001960 \pm 0.0003010)$ (table 2 , chart $3 \& 4$ ).

Table 2: The mean and the standard error of the mean of proinflammatory markers (MCP-1, IL-6 and TNFalpha) as well as anti-inflammatory marker (IL-10) in control ASCs (group I) versus primed ASCs (group II).

\begin{tabular}{|c|c|c|c|c|}
\hline Groups & $\begin{array}{l}\text { MCP-1/18S } \\
\quad(\text { R.E) }\end{array}$ & $\begin{array}{l}\text { IL-6/18S } \\
\text { (R.E) }\end{array}$ & $\begin{array}{c}\text { TNF- } \alpha / 18 S \\
(\text { R.E) }\end{array}$ & $\begin{array}{c}\text { IL-10/18S } \\
\text { (R.E) }\end{array}$ \\
\hline $\begin{array}{c}\text { Control ASCs (group } \\
\text { I) }\end{array}$ & $\begin{array}{l}56.45 \\
\pm 1.511\end{array}$ & $\begin{array}{c}16.86 \\
\pm 1.959\end{array}$ & $\begin{array}{c}0.001333 \\
\pm 0.0002275\end{array}$ & $\begin{array}{c}0.001960 \\
\pm 0.0003010\end{array}$ \\
\hline $\begin{array}{c}\text { Primed ASCs (group } \\
\text { II) }\end{array}$ & $\begin{array}{c}288.3 \\
\pm 25.75^{*}\end{array}$ & $\begin{array}{c}74.71 \\
\pm 4.892^{*}\end{array}$ & $\begin{array}{c}0.001733 \\
\pm 0.0002753\end{array}$ & $\begin{array}{c}0.001828 \\
\pm 6.270 \mathrm{e}-005\end{array}$ \\
\hline
\end{tabular}

\section{Chart 3}

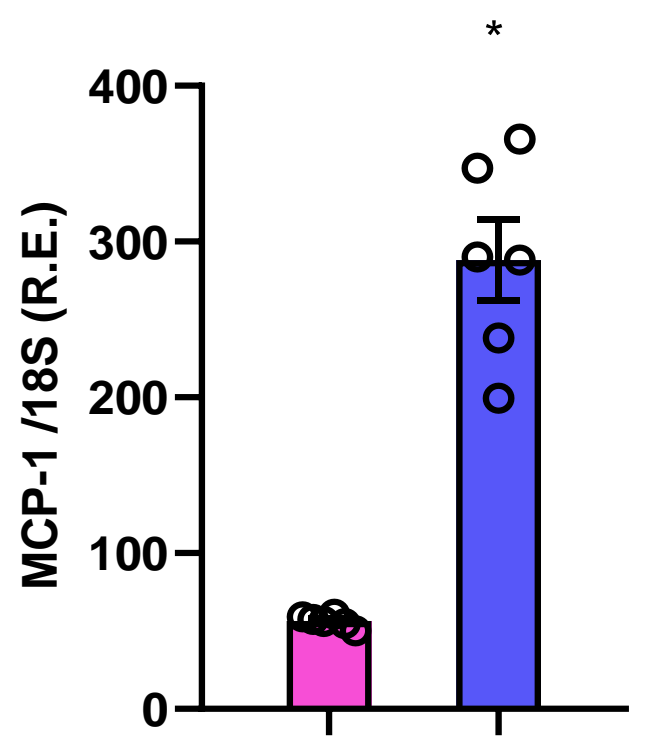

The mean and the standard error of the mean of MCP-1/18S in the two groups. chart 4

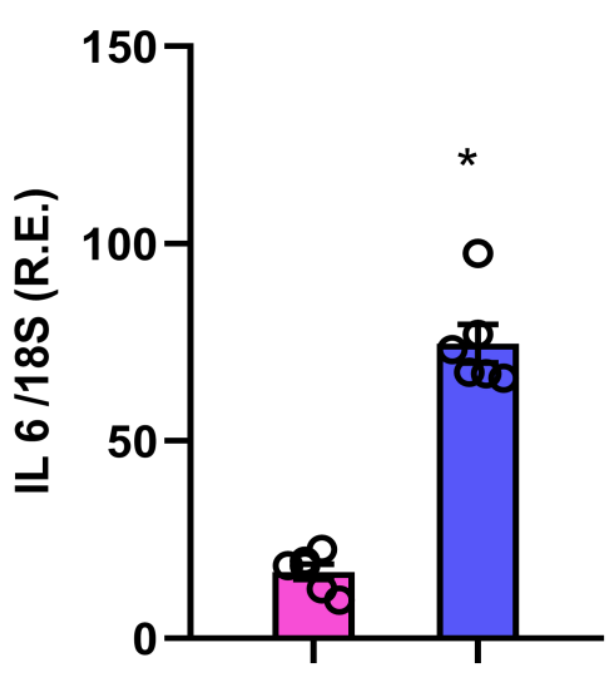

The mean and the standard error of the mean of IL-6/18S in the two groups 
Characterization of exosomes with transmission electron microscopy and western blot.

We have confirmed that our isolated extracellular vesicles were exosomes through both transmission electron microscopy, which showed that the vesicles' size ranged from 30-100 nm, and through western blotting of the exosomes' specific markers (CD81 and TSG-101).

Primed-ASCs-exosomes promote the migration of vascular smooth muscle cells.
Scratch assay showed that exosomes from primed ASCs (group III) resulted in significant $(p>0.05)$ increase in vascular smooth muscle cells migration (40.26 \pm 2.123$)$ compared to control ASCs exosomes (group II) $(22.53 \pm 2.863)$ and basal culture medium (group I) (16.65 \pm 1.824$)$. Similarly, control ASCs exosomes (group II) resulted in significant ( $>0.05)$ increase in vascular smooth muscle cells migration $(22.53 \pm 2.863)$ when compared with basal culture medium (group I) (16.65 \pm 1.824$)$ (table 3, chart 5 \& fig.1-3)

Table 3: Wound healing area \% of VSMCs incubated with basal culture medium (group I), CM with ASCs' exosomes (group II) and CM with treated ASCs' exosomes (group III) after 24 hrs of the scratch.

\begin{tabular}{cccc}
\hline $\begin{array}{c}\text { Assay } \\
\text { wells }\end{array}$ & $\begin{array}{c}\text { Group I } \\
\text { Wound healing area \% in } \\
\text { Control VSMCs + basal } \\
\text { culture medium after 24 hrs }\end{array}$ & $\begin{array}{c}\text { Group II } \\
\text { Wound healing area \% in } \\
\text { VSMosomes after 24 hrs }\end{array}$ & $\begin{array}{c}\text { Group III } \\
\text { Wound healing area \% in } \\
\text { VSMCs + CM with primed } \\
\text { ASCs' exosomes after 24hrs }\end{array}$ \\
\hline $\mathbf{1}$ & 20.91415 & 14.05688 & 33.70565 \\
$\mathbf{2}$ & 22.46451 & 21.86762 & 43.1831 \\
$\mathbf{3}$ & 17.3348 & 28.98651 & 43.1567 \\
$\mathbf{4}$ & 10.77303 & 31.67038 & 33.66594 \\
$\mathbf{5}$ & 14.83246 & 23.02641 & 45.47627 \\
$\mathbf{6}$ & 13.56237 & 15.59249 & 42.39805 \\
Mean \pm & $16.65 \pm 1.824$ & $22.53 \pm 2.863^{*}$ & $40.26 \pm 2.123^{\#}$ \\
SEM & & & \\
\hline
\end{tabular}

VSMCs: Vascular smooth muscle cells CM: culture medium ASCs: Adipose derived stem cells SEM: standard error of the mean. All values are mean $+/$-standard error. ${ }^{*}, \mathrm{P}<0.05$ is considered significant compared with Group I, using ANOVA test \#, $\mathrm{P}<0.05$ is considered significant compared with Group II using ANOVA test 


\section{Chart 5}

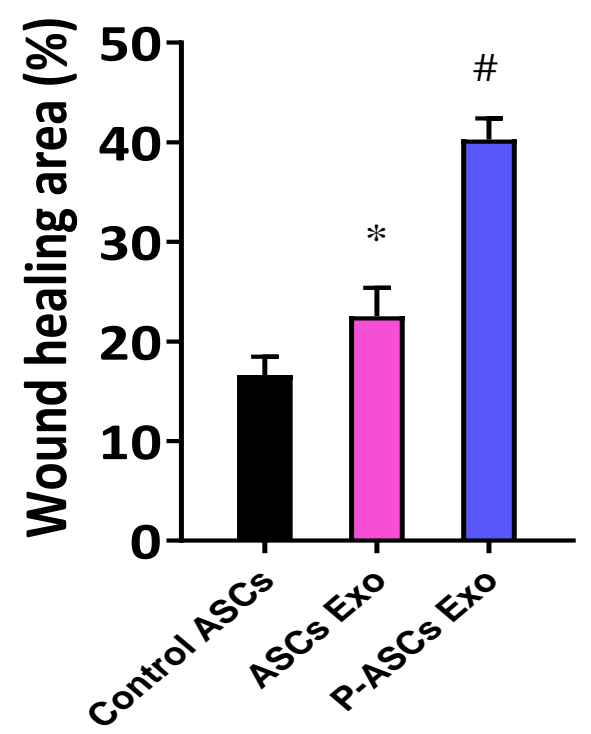

Wound healing area \% of VSMCs incubated with basal culture medium (group I), CM with control ASCs' exosomes (group II) and CM with primed ASCs' exosomes (group III) after 24 hrs. of the scratch.

$0 \mathrm{hr}$ $24 \mathrm{hrs}$

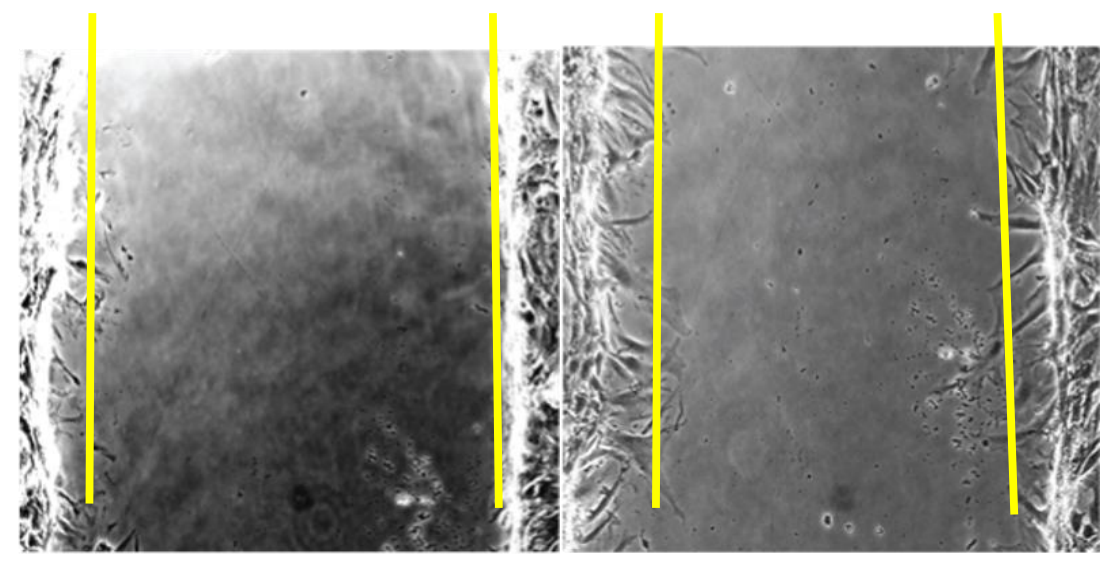

Figure 1: Wound healing area \% in Control VSMCs + basal CM at $0 \& 24 \mathrm{hrs}$ 
$\mathrm{Ohr}$

$24 \mathrm{hrs}$

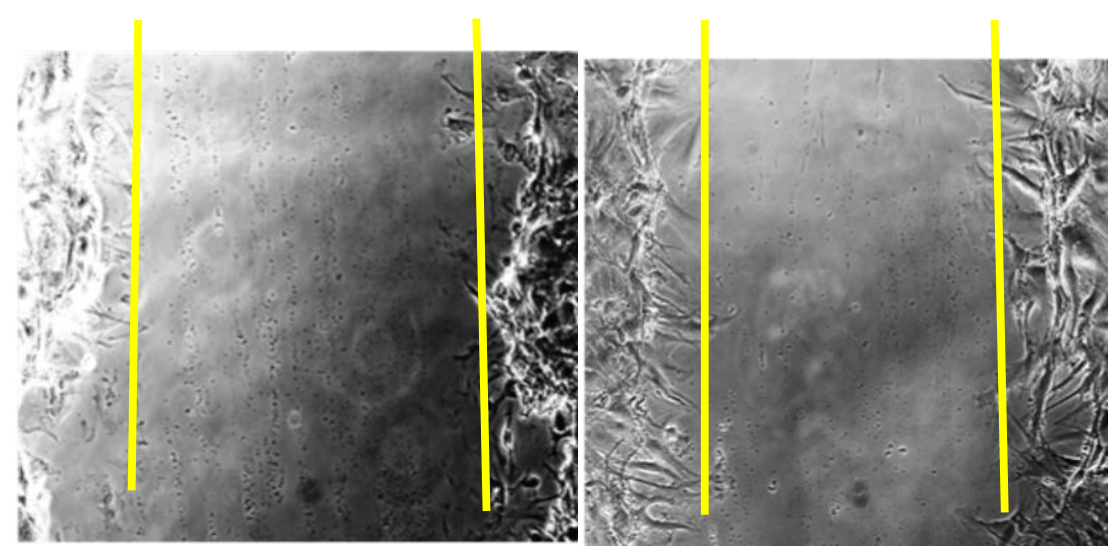

Figure 2: Wound healing area \% in Control VSMCs + CM with cont. ASCs'exosomes Ohr $24 \mathrm{hrs}$

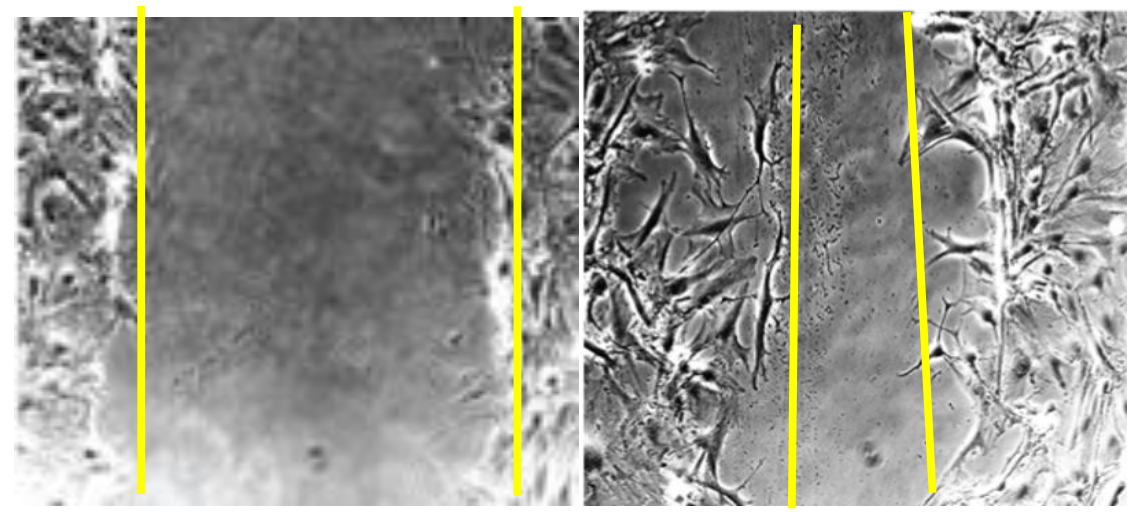

Figure 3: Wound healing area \% in Control VSMCs CM with primed ASCs'exosomes

\section{Discussion}

Cardiovascular disease is a leading health problem all over the world (35). Diabetic patients are two to four-fold more vulnerable to develop coronary artery diseases and around $70 \%$ of type 2 diabetic patients who are 65 years old or more die from

cardiovascular diseases (36). Recently adipose tissue has been addressed to play a crucial role in cardiovascular health, owing to its ability to secrete a wide variety of active molecules including adipokines and extracellular vesicles. Adipose tissue bioactive particles can have both endocrine 
and paracrine effects on cardiovascular system. Under physiological conditions adipose tissue derived molecules may possess an anti-inflammatory and ant atherogenic effect. However with systemic inflammation and insulin resistance adipose tissue may acquire a pro inflammatory and proatherogenic phenotype (37).

Pathological conditions such as; obesity and diabetes can alter PVAT secretome, as well as the phenotype of its resident and infiltrating cells (38).One of the resident cells in PVAT are, adipose-derived stem cells which play critical roles in controlling obesity-associated inflammation and metabolic disorders (39).

In order to figure out the possible role of PVAT adipose-derived stem cells in the pathogenesis of vascular diseases in diabetes, we started with culturing type 2 diabetic adipose-derived stem cells from PVAT. As we have experienced, type 2 diabetic adipose-derived stem cells were not easy to culture, had a slow growth rate and turned into adipocytes without induction of adipogenesis.

To overcome this obstacle, we thought to generate an in-vitro model of adiposederived stem cells which can replicate the inflammatory and metabolic dysfunction in obesity and type 2 diabetes. We treated adipose-derived stem cells with a cocktail of lipopolysaccharides to mimic the inflammatory state(40), palmitate to mimic the hyperlipidemia and insulin resistance (41) and high glucose to mimic the hyperglycemic conditions in type 2 diabetes (42).

After treatment of our cells with the cocktail for 24 hours, those primed adipose-derived stem cells showed significant $(\mathrm{p}<0.05)$ increase in the proinflammatory markers; interleukin-6, monocyte chemoattractant protein-1 and tumor necrosis factor-alpha.

Our results are in agreement with previous study, which showed that monocyte chemoattractant protein-1 and interleukin-6 gene expression were elevated in preadipocytes after treatment with palmitate or lipopolysaccharides (43). Activation of nuclear factor kappa pathways in the adipose-derived stem cells by lipopolysaccharides and palmitate is suggested to enhance the expression of the proinflammatory cytokines (44).

We then carried a metabolic assay for those adipose-derived stem cells to detect their oxygen consumption as well as extracellular acidification rates after treatment with our cocktail. Primed adipose-derived stem cells 
showed lower oxygen consumption rate at both basal and stressful conditions. Our study is in agreement with previous studies which showed that oxygen consumption rate in adipocytes from obese and diabetic mice and humans was reduced $(45,46)$.

The decreases in the oxygen consumption rate can be attributed to obesity induced mitochondrial dysfunction with consequent reduction in its oxidative capacity (47).

Although basal extracellular acidification rate in primed cells was lower than control cells, however after induction of stress both cells were able to increase their extracellular acidification rate with non-significant difference between the 2 groups .This can be explained by the composition of our cocktail, which contain palmitate and glucose. So, we provide the cells with substrates for glycolysis which may be the reason that the cells were able to increase their extracellular acidification rate even though they were metabolically dysfunctional.

Vascular smooth muscle cells phenotype switching is a hallmark in early and late atherosclerosis were VSMCs turn from the quiescent "contractile" phenotype state to the active "synthetic" state, that can proliferate and migrate from media to the intima (48).

Exosomes have now been recognized as a vital intercellular communicator, affecting a plethora of physiological and pathological processes (49).So, we decided to figure out the role of the ASCs derived exosomes in promotion of vascular smooth muscle cells migration.

After treating the ASCs with our cocktail for 24 hours, we collected the conditioned medium from both control adipose-derived stem cells and adipose-derived stem cells treated with cocktail to isolate exosomes.

Vascular smooth muscle cells migration was assessed via scratch assay after incubation with ASCs derived exosomes. As we have expected, the exosomes derived from primed ASCs promoted VSMCs migration compared to VSMCs incubated with CM from control ASCs or with basal CM.

Recently a research group has demonstrated that exosomes derived from adventitial fibroblasts from hypertensive rats promoted migration of vascular smooth muscle cells compared to those from normotensive rats (50). In another recent study, results have shown that exosomes derived from proinflammatory macrophages promote 
vascular smooth muscle cells migration and proliferation (51).

These results agree with our assumption that exosomes play a key role in intercellular communication, and that the effect of exosomes differ according to the cell condition.

Exosomes induction of vascular smooth muscle cells migration may be attributed to the stimulation of phenotype switching of vascular smooth muscle cells from quiescent contractile to synthetic migratory phenotype by exosomes' cargo; miRNAs and proteins (52).

\section{References}

1. Einarson TR, Acs A, Ludwig C, Panton UH. Prevalence of cardiovascular disease in type 2 diabetes: a systematic literature review of scientific evidence from across the world in 2007-2017. Cardiovascular diabetology. 2018;17(1):83.

2. Lotufo PA, Gaziano JM, Chae CU, Ajani UA, Moreno-John G, Buring JE, et al. Diabetes and all-cause and coronary heart disease mortality among US male physicians. Archives of internal medicine. 2001;161(2):242-7.

3. Soltis EE, Cassis LA. Influence of perivascular adipose tissue on rat aortic smooth muscle responsiveness. Clinical and experimental hypertension Part A, Theory and practice. 1991;13(2):277-96.
4. Liang $\mathrm{W}, \mathrm{Ye} \mathrm{DD}$. The potential of adipokines as biomarkers and therapeutic agents for vascular complications in type 2 diabetes mellitus. Cytokine \& growth factor reviews. 2019;48:32-9.

5. Feldmann HM, Golozoubova V, Cannon B, Nedergaard J. UCP1 ablation induces obesity and abolishes diet-induced thermogenesis in mice exempt from thermal stress by living at thermoneutrality. Cell metabolism. 2009;9(2):203-9.

6. Almind K, Manieri M, Sivitz WI, Cinti S, Kahn CR. Ectopic brown adipose tissue in muscle provides a mechanism for differences in risk of metabolic syndrome in mice. Proc Natl Acad Sci U S A. 2007;104(7):2366-71.

7. Villarroya F, Cereijo R, Gavaldà-Navarro A, Villarroya J, Giralt M. Inflammation of brown/beige adipose tissues in obesity and metabolic disease. Journal of Internal Medicine. 2018;284(5):492-504.

8. Zhu X-Y, Ma S, Eirin A, Woollard JR, Hickson LJ, Sun D, et al. Functional plasticity of adipose-derived stromal cells during development of obesity. Stem cells translational medicine. 2016;5(7):893-900.

9. Gimble JM, Katz AJ, Bunnell BA. Adiposederived stem cells for regenerative medicine. Circulation research. 2007;100(9):1249-60.

10. Ruiz JC, Ludlow JW, Sherwood S, Yu G, Wu X, Gimble JM. Differentiated human adiposederived stem cells exhibit hepatogenic capability in vitro and in vivo. Journal of cellular physiology. 2010;225(2):429-36.

11. Nakagami H, Maeda K, Morishita R, Iguchi S, Nishikawa T, Takami Y, et al. Novel autologous 
cell therapy in ischemic limb disease through growth factor secretion by cultured adipose tissue-derived stromal cells. Arteriosclerosis, thrombosis, and vascular biology. 2005;25(12):2542-7.

12. Wang $\mathrm{M}$, Crisostomo PR, Herring $\mathrm{C}$, Meldrum KK, Meldrum DR. Human progenitor cells from bone marrow or adipose tissue produce VEGF, HGF, and IGF-I in response to TNF by a p38 MAPKdependent mechanism. American Journal of Physiology-Regulatory, Integrative and Comparative Physiology. 2006;291(4):R880-R4.

13. Rehman J, Traktuev D, Li J, Merfeld-Clauss S, Temm-Grove CJ, Bovenkerk JE, et al. Secretion of angiogenic and antiapoptotic factors by human adipose stromal cells. Circulation. 2004;109(10):1292-8.

14. Badimon L, Cubedo J. Adipose tissue depots and inflammation: effects on plasticity and resident mesenchymal stem cell function. Cardiovascular research. 2017;113(9):1064-73.

15. Zhao L, Johnson $\mathrm{T}$, Liu D. Therapeutic angiogenesis of adipose-derived stem cells for ischemic diseases. Stem cell research \& therapy. 2017;8(1):125.

16. Rennert RC, Sorkin M, Januszyk M, Duscher D, Kosaraju R, Chung MT, et al. Diabetes impairs the angiogenic potential of adipose-derived stem cells by selectively depleting cellular subpopulations. Stem cell research \& therapy. 2014;5(3):79.

17. Ebrahim N, Ahmed IA, Hussien NI, Dessouky AA, Farid AS, Elshazly AM, et al. Mesenchymal Stem Cell-Derived Exosomes Ameliorated Diabetic Nephropathy by Autophagy
Induction through the mTOR Signaling Pathway. Cells. 2018;7(12).

18. Huang-Doran I, Zhang CY, Vidal-Puig A. Extracellular Vesicles: Novel Mediators of Cell Communication In Metabolic Disease. Trends in endocrinology and metabolism: TEM. 2017;28(1):318.

19. Eljaafari A, Robert M, Chehimi M, Chanon S, Durand C, Vial G, et al. Adipose tissue-derived stem cells from obese subjects contribute to inflammation and reduced insulin response in adipocytes through differential regulation of the Th1/Th17 balance and monocyte activation. Diabetes. 2015;64(7):2477-88.

20. He C, Medley SC, Hu T, Hinsdale ME, Lupu F, Virmani $\mathrm{R}$, et al. PDGFR $\beta$ signalling regulates local inflammation and synergizes with hypercholesterolaemia to promote atherosclerosis. Nature communications. 2015;6:7770.

21. Ikawati M, Kawaichi M, Oka C. Loss of HtrA1 serine protease induces synthetic modulation of aortic vascular smooth muscle cells. PloS one. 2018;13(5).

22. Li S-l, Reddy MA, Cai Q, Meng L, Yuan H, Lanting L, et al. Enhanced proatherogenic responses in macrophages and vascular smooth muscle cells derived from diabetic $\mathrm{db} / \mathrm{db}$ mice. Diabetes. 2006;55(9):2611-9.

23. Cui XB, Luan JN, Dong K, Chen S, Wang Y, Watford WT, et al. RGC-32 (Response Gene to Complement 32) Deficiency Protects Endothelial Cells From Inflammation and Attenuates Atherosclerosis. Arterioscler Thromb Vasc Biol. 2018;38(4):e36-e47. 
24. Nagata H, Ii M, Kohbayashi E, Hoshiga M, Hanafusa T, Asahi M. Cardiac Adipose-Derived Stem Cells Exhibit High Differentiation Potential to Cardiovascular Cells in C57BL/6 Mice. Stem cells translational medicine. 2016;5(2):141-51.

25. Luna AC, Madeira ME, Conceição TO, Moreira JA, Laiso RA, Maria DA. Characterization of adipose-derived stem cells of anatomical region from mice. BMC research notes. 2014;7:552.

26. Bagno LL, Carvalho D, Mesquita F, Louzada RA, Andrade B, Kasai-Brunswick TH, et al. Sustained IGF-1 Secretion by Adipose-Derived Stem Cells Improves Infarcted Heart Function. Cell transplantation. 2016;25(9):1609-22.

27. Palumbo P, Lombardi F, Siragusa G, Cifone MG, Cinque B, Giuliani M. Methods of Isolation, Characterization and Expansion of Human AdiposeDerived Stem Cells (ASCs): An Overview. Int J Mol Sci. 2018;19(7).

28. Ahmad R, Al-Roub A, Kochumon S, Akther N, Thomas R, Kumari M, et al. The Synergy between Palmitate and TNF-alpha for CCL2 Production Is Dependent on the TRIF/IRF3 Pathway: Implications for Metabolic Inflammation. J Immunol. 2018;200(10):3599-611.

29. Cheng X, Ni B, Zhang F, Hu Y, Zhao J. High Glucose-Induced Oxidative Stress Mediates Apoptosis and Extracellular Matrix Metabolic Imbalances Possibly via p38 MAPK Activation in Rat Nucleus Pulposus Cells. Journal of diabetes research. 2016;2016:3765173.

30. Murumalla RK, Gunasekaran MK, Padhan JK, Bencharif K, Gence L, Festy F, et al. Fatty acids do not pay the toll: effect of SFA and PUFA on human adipose tissue and mature adipocytes inflammation. Lipids in Health and Disease. 2012;11(1):175.

31. Zhu X, Tu Y, Chen H, Jackson AO, Patel V, Yin K. Micro-environment and intracellular metabolism modulation of adipose tissue macrophage polarization in relation to chronic inflammatory diseases. Diabetes/metabolism research and reviews. 2018;34(5):e2993.

32. Dinkins MB, Dasgupta S, Wang G, Zhu G, Bieberich E. Exosome reduction in vivo is associated with lower amyloid plaque load in the 5XFAD mouse model of Alzheimer's disease. Neurobiology of aging. 2014;35(8):1792-800.

33. Zeng M, Luo Y, Xu C, Li R, Chen N, Deng $\mathrm{X}$, et al. Platelet-Endothelial Cell Interactions Modulate Smooth Muscle Cell Phenotype in an vitro Model of Type 2 Diabetes Mellitus. Am J Physiol Cell Physiol. 2018.

34. Kassiri Z, Zhong J, Guo D, Basu R, Wang $\mathrm{X}$, Liu PP, et al. Loss of angiotensin-converting enzyme 2 accelerates maladaptive left ventricular remodeling in response to myocardial infarction. Circulation: Heart Failure. 2009;2(5):446-55.

35. Roth GA, Johnson C, Abajobir A, AbdAllah F, Abera SF, Abyu G, et al. Global, Regional, and National Burden of Cardiovascular Diseases for 10 Causes, 1990 to 2015. Journal of the American College of Cardiology. 2017;70(1):1-25.

36. Benjamin EJ, Blaha MJ, Chiuve SE, Cushman M, Das SR, Deo R, et al. Heart Disease and Stroke Statistics-2017 Update: A Report From the American Heart Association. Circulation. 2017;135(10):e146-e603. 
37. Oikonomou EK, Antoniades C. The role of adipose tissue in cardiovascular health and disease. Nature Reviews Cardiology. 2019;16(2):83-99.

38. Siegel-Axel D, Häring H. Perivascular adipose tissue: An unique fat compartment relevant for the cardiometabolic syndrome. Reviews in Endocrine and Metabolic Disorders. 2016;17(1):5160.

39. Zhao H, Shang Q, Pan Z, Bai Y, Li Z, Zhang H, et al. Exosomes from adipose-derived stem cells attenuate adipose inflammation and obesity through polarizing M2 macrophages and beiging in white adipose tissue. Diabetes. 2018;67(2):235-47.

40. Cao W, Huang H, Xia T, Liu C, Muhammad S, Sun C. Homeobox a5 Promotes White Adipose Tissue Browning Through Inhibition of the Tenascin C/Toll-Like Receptor 4/Nuclear Factor Kappa B Inflammatory Signaling in Mice. Front Immunol. 2018;9:647.

41. Cho YM, Kim DH, Lee KH, Jeong SW, Kwon OJ. The IRE1 $\alpha$-XBP1s pathway promotes insulin-stimulated glucose uptake in adipocytes by increasing PPAR $\gamma$ activity. Experimental \& molecular medicine. 2018;50(8):102.

42. Lin, Ying R, Berg AH, Iyengar P, Lam TK, Giacca A, et al. The hyperglycemia-induced inflammatory response in adipocytes the role of reactive oxygen species. Journal of biological chemistry. 2005;280(6):4617-26.

43. Dordevic AL, Konstantopoulos N, Cameron-Smith D. 3T3-L1 preadipocytes exhibit heightened monocyte-chemoattractant protein-1 response to acute fatty acid exposure. PLoS One. 2014;9(6):e99382.
44. Morita N, Hosaka T, Kitahara A, Murashima T, Onuma H, Sumitani Y, et al. Novel Mechanisms Modulating Palmitate-Induced Inflammatory Factors in Hypertrophied 3T3-L1 Adipocytes by AMPK. Journal of diabetes research. 2018;2018:9256482.

45. Rong JX, Qiu Y, Hansen MK, Zhu L, Zhang $\mathrm{V}$, Xie M, et al. Adipose mitochondrial biogenesis is suppressed in $\mathrm{db} / \mathrm{db}$ and high-fat diet-fed mice and improved by rosiglitazone. Diabetes. 2007;56(7):1751-60.

46. Wilson-Fritch L, Nicoloro S, Chouinard M, Lazar MA, Chui PC, Leszyk J, et al. Mitochondrial remodeling in adipose tissue associated with obesity and treatment with rosiglitazone. The Journal of clinical investigation. 2004;114(9):1281-9.

47. Yin X, Lanza IR, Swain JM, Sarr MG, Nair $\mathrm{KS}$, Jensen MD. Adipocyte mitochondrial function is reduced in human obesity independent of fat cell size. The Journal of clinical endocrinology and metabolism. 2014;99(2):E209-16.

48. Johnson JL. Emerging regulators of vascular smooth muscle cell function in the development and progression of atherosclerosis. Cardiovascular research. 2014;103(4):452-60.

49. Li, Na, Zhao L, Wei Y, Ea VL, Nian H, et al. Recent advances of exosomes in immunemediated eye diseases. Stem cell research \& therapy. 2019;10(1):278.

50. Tong Y, Ye C, Ren XS, Qiu Y, Zang YH, Xiong XQ, et al. Exosome-Mediated Transfer of ACE (Angiotensin-Converting Enzyme) From Adventitial Fibroblasts of Spontaneously Hypertensive Rats Promotes Vascular Smooth 
Benha medical journal vol. 38, academic issue, 2021

Muscle Cell Migration. Hypertension. 222/CDKN1B/CDKN1C pathway. Cell death \& $2018 ; 72(4): 881-8$. disease. $2019 ; 10(6)$.

51. Wang, Zeng, Zhu H, Shi H, Zhao H, Gao R, 52. Zhang, Ming-Jie, Zhou Y, Chen L, Wang Yet al. Exosomes derived from M1 macrophages aggravate neointimal hyperplasia following carotid artery injuries in mice through miRQ, Wang X, et al. An overview of potential molecular mechanisms involved in VSMC phenotypic modulation. Histochemistry and cell biology. 2016;145(2):119-30.

To cite this article: Noura N. Ballasy, Vaibhav Patel, Noha I. Hussien, Ola A. El-Gohary, Alaa El Deen El-Talees. Role of exosomal intercellular communications in diabetic vascular complications in experimental animals. BMFJ 2021;38 (academic issue);11-29. DOI: $10.21608 / \mathrm{bmfj} .2020 .25853 .1228$ 